\title{
Participatory rural appraisal and farmers' perception about common bean varieties in temperate Kashmir
}

\author{
Fayaz A. Sheikh ${ }^{1}$, Parvez A. Sofi ${ }^{1}$, M. Nisar Khan ${ }^{1}$ Najeeb. R. Sofi ${ }^{2}$, Shabir H. Wani ${ }^{2}$ and \\ M. A. Bhat ${ }^{1}$ \\ ${ }^{1}$ Division of Genetics and Plant Breeding FoA, Wadura, Sopore, Baramulla -193201 (J\&K), INDIA \\ ${ }^{2}$ Mountain Research Centre for Field Crops, , Sher-e- Kashmir University of Agricultural Sciences and Technology \\ Kashmir, Khudwani Anantnag-192101 (J\&K), INDIA \\ *Corresponding author. E-mail: shabirhussainwani@gmail.com
}

Received: September 25, 2016; Revised received: January 31, 2017; Accepted: May 25, 2017

\begin{abstract}
Present investigation was undertaken during 2012 to 2014 in which 54 genotypes, both pole and bush type of Common beans (Phaseolus vulgaris) were selected among a number of germplasm lines, land races and research material in order to generate information on the farmer's' perception about the Common bean varieties. Participatory rural appraisal was conducted in 32 villages of Kashmir through a broad questionnaires comprising of questions pertaining to the socio-economic conditions, farming systems, production constraints and varietal preferences of the common bean. The Participatory Rural Appraisal results revealed that common bean is generally grown as a rainfed crop (70 \%) and is intercropped with maize/ potato/vegetable and merely as sole crop (20.66 \%). Low yielding varieties and diseases $(68.27 \%)$ are considered as major challenges in the success of common bean crop, while as red colour with kidney shaped types (50\%) are highly being preferred as a pulse crop. The exercise of Participatory Rural Appraisal was carried out to generate basic information by assessing the need based constraints and devise the target breeding approach, by taking into consideration all constraints and also devise future breeding programme. A successful PRA provides the information needed to specify the characteristic in a new variety regarding its physical environment and the existing varietal diversity. For a breeding program, well applied Participatory Rural Appraisal techniques or customer profiling results in better client orientation and makes possible efficient goal setting or product design. Successful PRA provides everything that could be included in the full design specification of a new crop variety.
\end{abstract}

Keywords: Common Bean, Farming systems, Participatory Rural Appraisal, Questionnaires

\section{INTRODUCTION}

Common bean (Phaseolus vulgaris L.) is the most important pulse crop of the world covering about half of the global pulse acreage. In terms of use category common bean is classified as dry or pulse type and snap or vegetable types. Snap beans are also called as French beans, String beans, Green beans or Squeaky beans. Despite being called as "Grain of Hope" and "Poor man's Meat", this pulse crop has not received the just attention from breeders, farmer's and policy makers alike due to inherently low yield of pulses, relegation to harsh environments, lack of major technological breakthrough and the lack of encouraging market and price support from the government. Participatory methods have been used to gather information on important traits, and in facilitating the targeting of breeding programmes for greater impact (Witcombe et al., 2005). Farmer's' can provide useful information on plant types, desired traits and insight into trade-offs they are willing to make among traits in designing cultivar types (Sperling et al., 2001).
Therefore, if the farmer's priorities, needs and capacities are valued and better understood by researchers, appropriate and sustainable recommendations can be made and thus, increase chances of adoption of new technologies (Scoones and Thompson, 1994). The level of participation may vary depending upon the stage of participatory plant breeding programme but participation has to be effective at all the stages. Appropriate client orientation mechanism in the form of participatory rural appraisal has to be done in order to generate basic data for varietal specifications and decide the stages and levels of participation of farmer's.

The PRA, when employed in PPB, focuses on the issues relating to the particular target crop. Based on the appraisal of twelve participatory plant breeding (PPB) programmes (Witcombe et al. 2006) concluded that collaboration with farmer's at the selection stage globally showed favourable results. He further reported that, compared with formal programmes managed on-station by professional breeders, the PPB programmes may seldom produce genotypes with 
significantly higher yields, but more often cultivars with an improved balance of traits such as earliness, yield and grain quality can be identified. Birachi et al. 2011 in his study came out with a list of constraints faced by bean growers that limit the production levels including losses during storage and transportation, distance from market, bean prices etc (Njoki, 2013). while surveying in Kiambu County in Kenya using a semi-structured questionnaire, interviews, and focus group discussions, found that farmer's' cultivate Common bean during the short and long rain seasons. However, they experience better yields in the short rains due to reduced disease incidence (Sheikh 2014), carried out Participatory rural appraisal (PRA) at sixteen selected sites by predesigned questionnaire and it helped him to know the farmer's preferences and perceptions regarding different traits of French bean. The data revealed that farmer's preferred genotypes with traits like early maturing, higher yield, string-less pods, white coloured seed and freedom from diseases. Participatory rural appraisal (PRA) was carried out at different locations of Kulgam and Shopian (Umar 2015). The data of PRA at selected sites revealed that farmer's preferred those genotypes having early maturing, higher yield, red coloured seeds, plain coat and tolerance to drought and freedom from diseases. Therefore, the present investigation was carried out to generate information on the farmer's' perception about the Common bean varieties under Kashmir conditions.

\section{MATERIALS AND METHODS}

In order to get an insight into the production constraints and livelihood opportunities of common bean in Kashmir participatory rural appraisal was done in the study areas. A questionnaire was drafted in light of available literature and ground information, that aimed at creating a baseline information about the socio-economic status, production systems, management systems, varietal preferences, constraints and opportunities of common bean growing farmer's of the areas of study. The questionnaire used for PRA is presented in Appendix-I. At an average the number of farmer's who participated in participatory rural appraisal across various locations were 28 among whose the number of respondents were 22 only. The PRA questionnaire was structured in light of the suggestions made by Professor John Witcombe (per's communication) and different parameters were grouped under appropriate heading to get an insight in to the socioeconomic attributes, farming system attributes, production constraints, varietal attributes and other relevant information. Flexible approach was used in PRA to derive any other information provided by farmer's that was as such not covered within the contents of PRA questionnaire. The results of PRA were analyzed by using t-test to assess the homogeneity of data recorded. The calculated value of $t$ test was tested against tabulated value of t test at 30 degrees of freedom. There were 13 questions in the questionnaire and the questions were asked in vernacular language and were filled in by the researcher himself after listening to the replies and understanding farmer's' production constraints

\section{RESULTS AND DISCUSSION}

Plant breeding impacts people and societies because it determines the course of our agricultural future. Without appropriate varieties that are relevant for their particular farming systems, farmers cannot be successful and consumers suffer from either price increases or lack of food availability, or both. PPB is a useful methodology that has enabled breeders and farmers in the developing world to create varieties adapted to the marginal conditions of many subsistence farms. PPB accomplishes this by taking advantage of $G \times E$ interaction, and selecting varieties directly in the environment of their intended use in order to achieve superior performance. Farmer participation is a crucial aspect of the methodology, as the farmer is best equipped to recognize the agronomic and quality traits that will enable the variety to be productive in his or her system (Shelton et al., 2016).

The present investigation was undertaken to generate baseline information about the farmer's production constraints, varietal preferences and livelihood opportunities associated with common bean in North Kashmir. Under the university's renewed focus on adding relevance to varietal developmental process, common bean was identified as one of the target crops in view of its niche status as well as continuing dismal performance of pulses due to a host of socio-economic, biological farming system as well as production constraints. The present study aimed at identification of farmer and non-farmer attributes of common bean based farming system as well as farmer's varietal preferences that meet their aspirations (Joshi et al., 2002). A successful PRA provides the information needed to specify the characteristic in a new variety regarding its physical environment and the existing varietal diversity. For a breeding program, well applied PRA techniques or customer profiling results in better client orientation and makes possible efficient goal setting or product design (Sumberg and Reece, 2004). Successful PRA provides everything that could be included in the full design specification of a new crop variety. Similar study was carried out by Rafiq et al. (2016) in Rice, during which PRA was conducted and provide feedback to breeders to breed such varieties for mountain irrigated agro-ecologies particularly for Kashmir valley as possess high biomass and grain yield with blast and cold resilience, high tillering, tall stature, medium threshing and medium bold seed with white milled grain colour preferably with aroma. The most preferred genotypes identified by the FGD 
through PVS need to be evaluated further by baby trial evaluation system on big plot size and over many more locations to corroborate the real performance and finally to recommend the varieties for up scaling through participatory seed production. The same genotypes were also identified as the most stable across all the test environments/locations for yield and other desirable traits put emphasis on the role of further evaluation both spatially and temporally so that the recommendation of genotypes can be suggested supported by data (Rafiq et al., 2016). The results obtained from the PRA across various locations are summed up below.

Ranking of common bean among Kharif pulses: The common bean (Phaseolus vulgaris L.) grown as main season Kharif crop across all locations among all pulses ranked first in cultivation when compared with other pulse crops $(82.09 \%)$. The ranking of common bean was done with other pulses. Generally the comparison was with the mung and the cow pea.

Farming practices (mixed crop versus sole crop+ inter-crop): Common bean is being widely grown as mixed crop $(79.34 \%)$ with maize, potato and vegetable. However at various locations, considerable number of farmer's' were also growing common bean as a sole crop.

Irrigation system (Rainfed versus assured): Data of farming practice across thirty two locations revealed that when farmer's' were asked about the source of irrigation system, it was found that crop was mostly grown under rainfed conditions $(70.3 \%)$.

Biotic stresses (disease resistance verses insect pest and weeds): Among all biotic stresses like diseases, pests, weeds etc. diseases especially BCMV was identified as a major production constraint by about $68.27 \%$ farmer's'. Among the biotic stresses and in this regard disease resistance was compared with insect pest and weeds. Of the total, only $32.73 \%$ of farmer's' opined that insect pest and weeds pose a threat to the production of common bean.

Abiotic stresses (Drought tolerance vs cold tolerance): The major abiotic production constraint which hampers the common bean production is drought tolerance $(73.10 \%)$.

Yield (Grain yield verses pod load and others): In this case substantial number of farmer's (54.41\%) pointed out that it is grain yield which is more preferred over other traits like culinary and cooking.

Understanding farmer's varietal preferences- Source of seed (Farmers' own seed versus market + institution): Regarding the source of seed, significant number of the selected farmer's' reported that they use their own seed $(78.10 \%)$ for production of common bean at all the locations. It is because of the limited supply of seed from all the government and semi-government/private sources which compels the farmer to use his own saved seed.
Colour of seed (Small red versus others (Kidney white + Kidney red + white navy + chocolate black): Regarding colour of seed, 50 per cent of the farmer's' favoured small red varieties as demand for such type of seed of common bean at market is more. Although kidney red and other coloured varieties (50 $\%$ ) of common bean are also preferred almost at all locations to a varying extent.

Seed coat pattern (plain versus mottled): Farmer's' almost across all location like plain seed coat $(71.83$ $\%$ ) and this trait scored highest as compared to mottled. However, in practical utility both the seed types are consumed by the farmer's' in a bigger proportion.

Seed shape (Kidney versus oval + Cuboidal + Cylindrical): Regarding seed type, 50 percent of the farmer's' favoured kidney shaped beans genotypes, as it is socially and ecologically fit under their production system followed by oval. Cuboidal and cylindrical types were disliked by most of farmer's.

Maturity (Earliness versus uniform maturity): Maturity is one of the most important traits in common bean. Earliness was more preferred by farmer's' across all the locations as 87.04 percent of the farmer's opined in this favour, because they want to save the crop from the terminal drought, which effects the crop to a considerable limit, at later stages of growth.

Market (seed size verses seed shape and others): The market attribute of common bean was assessed through seed size, shape and others and in this regard seed size was compared with seed shape and others. It was seed size (58.71 percent of farmer's opined in this favour) which catches the attention of the famers than seed shape and others.

Culinary traits (Taste versus cooking time + swelling / flatulence and others): The perceptions of farmer's' regarding the nature of culinary traits revealed that significant number of farmer's' $(56.20 \%)$ preferred common bean with good swelling character and a variety that cooks at a considerable short period of time with good taste.

Analytical methods: The t-test comparison analysis of participatory rural appraisal (PRA) comes out to be significant for most of the traits compared. In general, the t-test revealed that most of farmer's' across all thirty two locations cultivate beans as pulse crop, as a mixed crop mostly with maize and the seed to be used to raise the next season crop for cultivation was farmer's' own saved seed under rain-fed conditions. Due to a limited production of the seed by the government and private sector, it doesn't meet the requirements of the farmer.

Common bean in farming system: The results revealed that common bean was the most preferred summer season pulse crop ahead of cowpea and mung. This is invariably due to inherent cultural and farming system attributes of this crop including ability to fit in 
Fayaz A. Sheikh et al. / J. Appl. \& Nat. Sci. 9 (2): 1256 - 1263 (2017) 
Fayaz A. Sheikh et al. / J. Appl. \& Nat. Sci. 9 (2): 1256 - 1263 (2017)

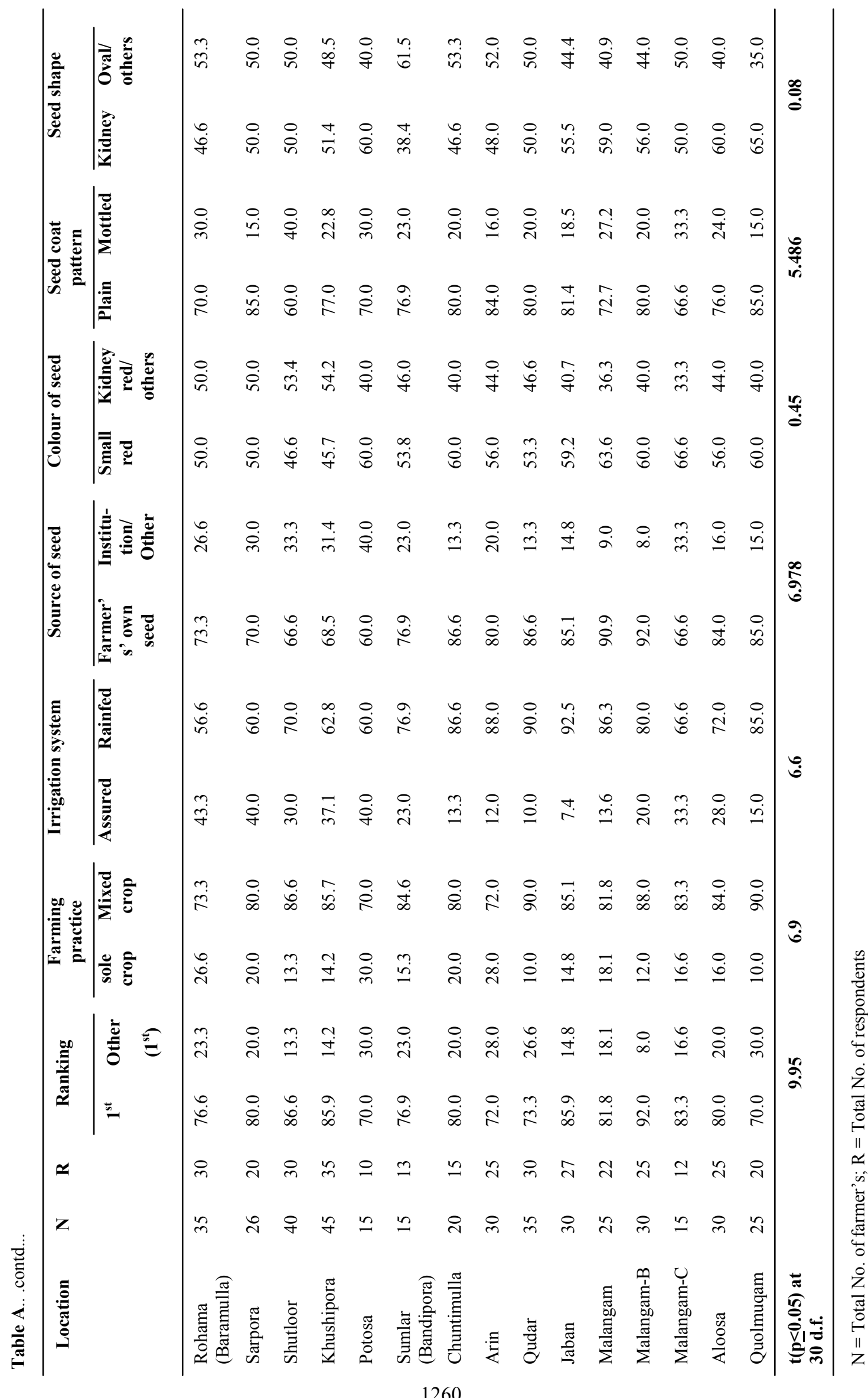


Fayaz A. Sheikh et al. / J. Appl. \& Nat. Sci. 9 (2): 1256 - 1263 (2017)

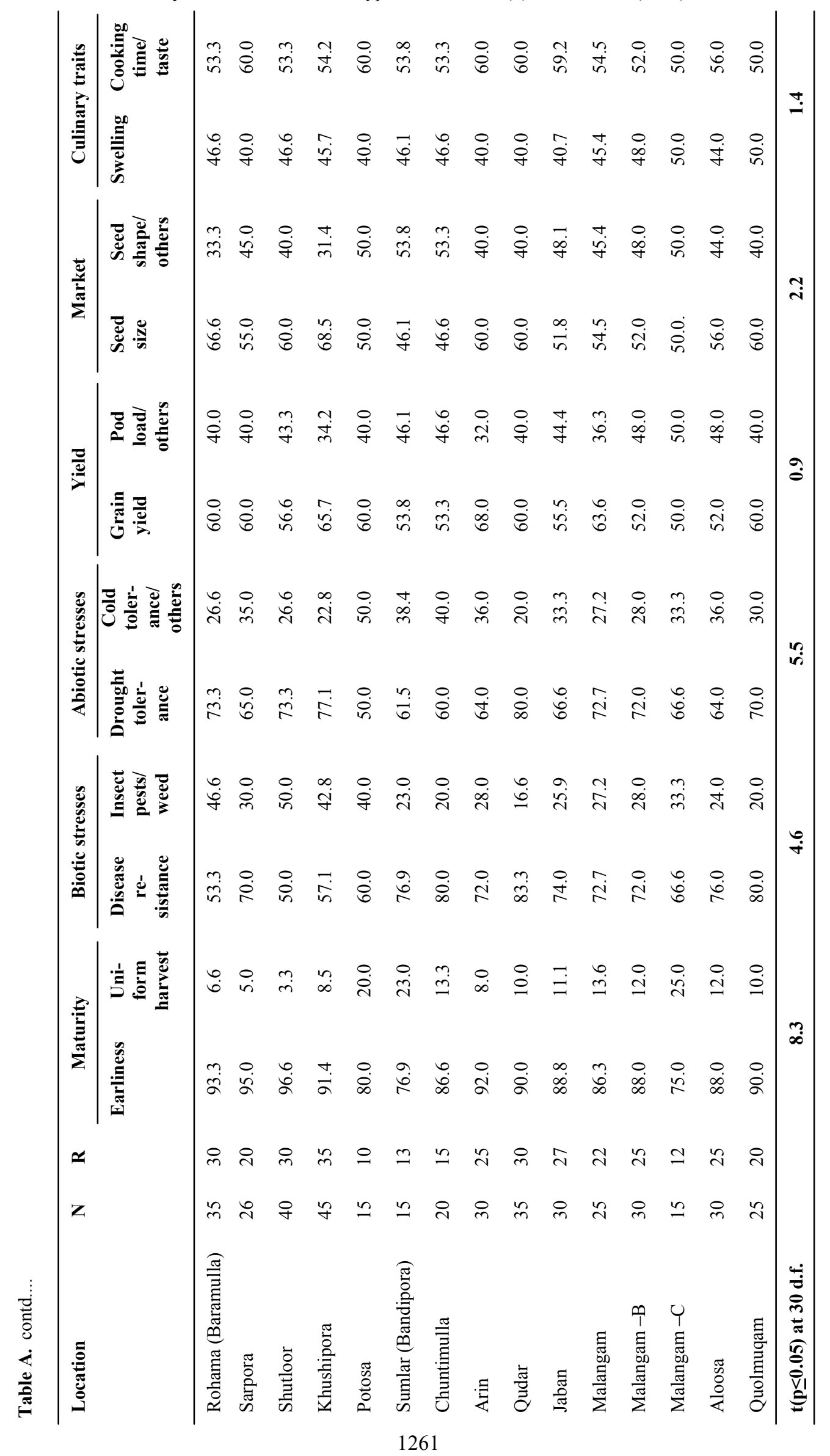


QUESTIONNAIRE DESIGNED FOR PRA IN COMMON BEAN

Rajmash Variety Evaluation Questionnaire

DISTRICT:-

LOCATION:-

\begin{tabular}{|c|c|c|c|}
\hline S. NO. & ATTRIBUTE/TRAIT & RANKING /SCALES/OPTIONS & RESPONSE \\
\hline 1 & $\begin{array}{l}\text { RANKING OF RAJMASH AMONG } \\
\text { KHARIF PULSES }\end{array}$ & $1-\mathrm{N}$ & \\
\hline 2 & FARMING PRACTICES & $\begin{array}{l}\text { SOLE CROP } \\
\text { MIXED CROP }\end{array}$ & \\
\hline 3 & IRRIGATION SYSTEM & $\begin{array}{l}\text { ASSURED IRRIGATION } \\
\text { RAINFED }\end{array}$ & \\
\hline 4 & SOURCE OF SEED & $\begin{array}{l}\text { FARMERS SAVED SEED } \\
\text { INSTITUTION/UNIVERSITY } \\
\text { ANY OTHER }\end{array}$ & \\
\hline 5 & COLOUR OF SEED & $\begin{array}{l}\text { SMALL RED } \\
\text { KIDNEY RED } \\
\text { OTHERS }\end{array}$ & \\
\hline 6 & SEED COAT PATTERN & $\begin{array}{l}\text { PLAIN } \\
\text { MOTTLED }\end{array}$ & \\
\hline 7 & SEED SHAPE & $\begin{array}{l}\text { KIDNEY } \\
\text { OVAL } \\
\text { OTHERS }\end{array}$ & \\
\hline 8 & MATURITY & $\begin{array}{l}\text { EARLINESS } \\
\text { UNIFORM HARVEST }\end{array}$ & \\
\hline 9 & BIOTIC STRESS & $\begin{array}{l}\text { DISEASE RESISTANCE } \\
\text { INSECT RESISTANCE } \\
\text { WEED RESISTANCE }\end{array}$ & \\
\hline 10 & ABIOTIC STRESS & $\begin{array}{l}\text { DROUGHT TOLERANCE } \\
\text { COLD TOLERANCE } \\
\text { OTHERS }\end{array}$ & \\
\hline 11 & YIELD & $\begin{array}{l}\text { GRAIN YIELD } \\
\text { POD LOAD } \\
\text { OTHERS }\end{array}$ & \\
\hline 12 & MARKET & $\begin{array}{l}\text { SEED SIZE } \\
\text { SEED SHAPE } \\
\text { OTHERS }\end{array}$ & \\
\hline 13 & CULINARY & $\begin{array}{l}\text { COOKING TIME } \\
\text { SWELLING } \\
\text { TASTE } \\
\text { OTHERS } \\
\end{array}$ & \\
\hline
\end{tabular}

both sole and mixed cropping, short duration, building soil fertility, ability to sustain yields under limited water and input support and ability to fetch substantial revenue in short duration in view of rising prices of pulses.

\section{Conclusion}

In order to assess the farm and non-farm characteristics of common bean based farming systems, a PRA was undertaken in Kashmir using a structured questionnaire that sought to develop baseline information about the farming systems, production constraints, varietal specifications and livelihood opportunities. In Farming system characteristics, Rajmash grown as a mixed crop with maize, potato and vegetables seldom grown as a sole crop, is the major summer season pulse crop of Kashmir Valley, where Farmer's saved seed is the major source of seed $(78.10 \%)$ with institutional support as little as $(21.90 \%)$. It is invariably grown as a rainfed $(70.3 \%)$ crop. In Production constraints, the low yield of existing varieties, even the Shalimar Rajmash-1 has yield potential of 1-1.2 t/ha under optimum management. The Drought stress $(73.10 \%)$ that strikes as early, intermittent and terminal drought is the major abiotic stress, limiting yield of rajmash. The Diseases namely BCMV, Anthracnose, Angular leaf spot etc. $(68.27 \%)$ are major biotic stresses and existing varieties are highly susceptible. Especially in case of BCMV, which is a seed borne disease; continuation of farmer's' own saved seed ensures that disease comes in mild or severe form every year depending upon environmental conditions. As for as Varietal specifications, Pole type varieties with small 
seed and red colour were invariably preferred owing to its greater market value $(50 \%)$, and that could fit into mixed cropping system are preferred. The early maturity was a preferred trait $(87.04 \%)$, since it helps farmer's' avoid the terminal drought especially in the months of June and July which are largely hot and dry. However early to cook and taste are preferred attributes in view of the energy issues $(56.20 \%)$ market value as well as the cultural attributes associated with the crop.

\section{REFERENCES}

Birachi, E., Ochieng, J., Wozemba, D., Ruraduma, C., Nijichire, M. and Ochieng, D. (2011). Factors influencing small holder bean farmers' production and supply to market in Burundi. African Crop Science Journal, 19(4): 335-342

Joshi, K. D. and Witcombe, J. R. (2002). Participatory varietal selection in rice in Nepal - a comparison of two methods by farmer's selection and varietal adoption. Euphytica, 127:445-458

Njoki, N. (2013). Breeding for durable resistance to angular leaf spot (Pseudocercospora griseola) in common bean (Phaseolus vulgaris) in Kenya. $\mathrm{PhD}$ thesis submitted to University of KwaZulu-Natal, Pp. 156

Rafiq, M., S. Najeeb, Sheikh, F. A., Iqbal, A. M., Bhat, Z. A., Kashyp, S. C., Hussian, A., Mujtaba, A. and Parray, G. A. (2016). Farmer's Participatory Varietal Selection in Japonica Rice (Oryza Sativa L.) in Kashmir Valley. SABRAO. Journal of Breeding and Genetics, 48 (2): 200-209, 2016

Scoones, I. and Thompson, J. (1994). Beyond Farmer First:
Rural People's knowledge, agricultural research, and extension practice. London: Intermediate Technology Publications.

Sheikh, A. (2014). Participatory Varietal selection in French beans in Ganderbal and Budgam districts of Kashmir using modified mother trial approach. M.Sc. Thesis submitted to SKUASTK, Shalimar. $112 \mathrm{Pp}$.

Shelton, A. C. and Tracy, W. F. (2016). Participatory plant breeding and organic agriculture: A synergistic model for organic variety development in the United States. Elementa: Science of the Anthropocene, 4: 000143.

Sperling, L., Ashby, J. A., Smith, M. E., Weltzein, E. and McGuire, S. (2001). A framework for analyzing participatory plant breeding approaches and results. Euphytica, 122: 439-450

Sumberg, J. and Reece, D. (2004). Agricultural research through a new product development lens. Experimental Agriculture, 40: 295-314

Umar, Gul. (2015). Participatory Varietal selection in Common bean in Kulgam and Shopian districts of Kashmir using modified mother trial approach. M. Sc. Thesis submitted to SKUAST-K, Shalimar. $112 \mathrm{Pp}$.

Witcombe, J. R., Joshi, K. D., Gyawali, S., Musa, A. M., Johansen, C., Virk, D. S. and Sthapit, B. R. (2005). Participatory plant breeding is better described as highly client-oriented plant breeding. I. Four indicators of client-orientation in plant breeding. Experimental Agriculture, 41(03): 299-319

Witcombe, J. R., Gyawali, S., Sunwar, S., Sthapit, B. R. and Joshi, K. D. (2006). Participatory plant breeding is better described as highly client-oriented plant breeding. II. Optional farmer collaboration in the segregating generations. Exp. Agric., 42: 79-90 